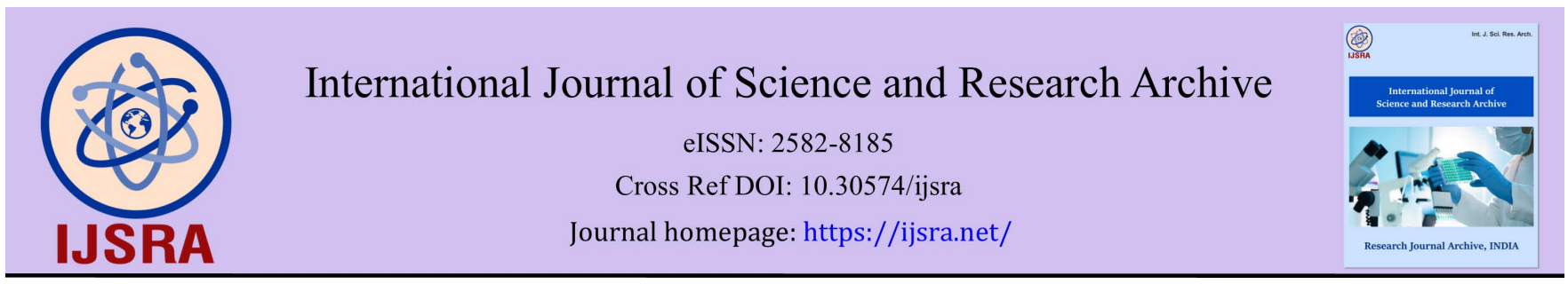

(RESEARCH ARTICLE)

\title{
Sero-prevalence of Hepatitis B virus and plasmodium co-infection profile among patients in Wukari and Environs, North East Nigeria
}

Edobor Peter Kenneth Imarenezor*, Onolunosen Abel Abhadionmhen, Sunday Danya, Joyce Briska and Paula Paul Shinggu

Tropical Diseases Unit, Department of Microbiology, Faculty of Pure and Applied Sciences, Federal University Wukari, Taraba State, Nigeria.

International Journal of Science and Research Archive, 2021, 03(01), 114-123

Publication history: Received on 12 July 2021; revised on 19 August 2021; accepted on 21 August 2021

Article DOI: https://doi.org/10.30574/ijsra.2021.3.1.0120

\begin{abstract}
Hepatitis B virus and plasmodium co-infection is of an increase in developing countries as a result of lack of proper diagnosis leading to increased morbidity. This study was to determine the sero-prevalence of Hepatitis B Virus and Plasmodium co-infection profile among patients in Wukari and environs. Seventy (70) subjects' with the age range of between 0 to 80 years participated and standard microbiological techniques were observed in this study. The results obtained showed 34 (48.6\%) were males and 36 (51.4\%) were females. Four (5.7\%) participants were sero-positive for HBsAg. HBsAb, HBcAb, HBeAg and HBeAb while 66 were not detected positive. The Male with 5.9\% participants were sero-positive while $5.6 \%$ of the female participants were sero-positive. 20 (28.6\%) of the participants were seropositive for malaria. This comprises of 7 males and 13 females. $20.6 \%$ of the males were sero-positive while $36.1 \%$ of the females were sero-positive. The distribution of parasitaemia by gender across the participants showed that 24 $(34.3 \%)$ had plasmodium parasitaemia, out of which 9 were males and 15 were females. $26.5 \%$ of the males and $41.7 \%$ of the females had plasmodium parasitaemia. There was no co-infection of Hepatitis B virus and malaria, despite both having prevalence of $5.7 \%$ and $34.3 \%$ respectively. The research on its own has shown that in order to reduce HBV and plasmodium co-infection, mass immunization of adults and antiviral drugs should be provided for those that are infected, while HBV and plasmodium co-infections screening programs should be instituted in all levels of institutions in the country to reduce the prevalence rate and level of transmission of the hepatitis virus. This study also has added to the puddle of knowledge already available in this area of research.
\end{abstract}

Keywords: Hepatitis B Virus; Patients; Plasmodium; Wukari, Sero-prevalence

\section{Introduction}

The oldest evidence of hepatitis B infection dates to Bronze Age [1]. The evidence was obtained from 4,500-year-old human remains by shotgun sequencing of the viral genomes [1]. [1], has described it as the oldest ever recovered from vertebrate samples. The divergence of orthohepadnavirus and avihepadnavirus occurred about 125,000 years ago and both the Avihepadnavirus and Orthohepadna viruses began to diversify about 25,000 years ago [2]. The branching at this time led to the emergence of the Orthohepadna genotypes A-H. Human strains have a most recent common ancestor dating back to 7,000 to 10,000 years ago. A second estimate of the origin of this virus suggests a most recent common ancestor of the human strains evolved around 1500 years ago [3]. The most recent common ancestor of the avian strains was placed at 6000 years ago. The mutation rate was estimated to be approximately $10^{-6}$ substitutions/site/year. Another analysis with a larger data set suggests that Hepatitis B infected humans 33,600 years ago [4]. Examination of sequences in the zebra finch have pushed the origin of this genus back at least to 40 million

\footnotetext{
${ }^{*}$ Corresponding author: Edobor Peter Kenneth

Tropical Diseases Unit, Department of Microbiology, Faculty of Pure and Applied Sciences, Federal University Wukari, Taraba State, Nigeria.
} 
years ago and possibly to 80 million years ago [5]. Chimpanzee, gorilla, orangutan, and gibbon's species cluster with human isolates. Non primate species included the woodchuck hepatitis virus, the ground squirrel hepatitis virus and arctic squirrel hepatitis virus. A number of bat infecting species have also been described. It has been proposed that a New World bat species may be the origin of the primate species [6]. A study of isolates from the circumpolar Arctic human population has proposed that the ancestor of the sub genotype B5 (the endemic type found in this population) that the ancestral virus originated in Asia about 2000 years ago (95\% HPD 900 BC - 830 AD) [7]. Coalescence occurred about 1000 AD. This sub genotype spread from Asia initially to Greenland_and then spread westward within the last 400 years. It was also found that some ancient hepatitis viral strains still infect humans, while other became extinct [1]. This disproved the belief that hepatitis B originated in the New World and spread to Europe around 16th century [1]. Hepatitis B Virus (HBV) is a DNA virus of the family hepadnaviridae and causes diseases resulting in liver conditions that could be of immense danger to human health [8]. It is a major cause of liver disease morbidity and mortality worldwide. There is a 15-25\% risk of dying prematurely in adulthood from HBV-related cirrhosis and hepatocellular carcinoma, while a small proportion of those with acute infections may also succumb to fulminant liver failure [9]. Malaria is a mosquito borne disease in humans caused by parasitic protozoans of the genus Plasmodium [10]. Human malaria is caused by five different species of Plasmodium namely, Plasmodium. Falciparum, P. vivax, P. ovale, P. malariae, and P. knowlesi [11]. falciparum and P. vivax are the most lethal [8]. An obligate intracellular parasite, Plasmodium requires two hosts to complete its life cycle, that is, an arthropod vector for sexual life cycle and human host for asexual life cycle. The mosquitoes which act as vector for this disease are female Anopheles funestus, Anopheles moucheti, Anopheles gambiae, Anopheles arabiensis [12]. The symptoms of malaria include abdominal discomfort, headache, joint aches, muscle aches, abdominal discomfort, vomiting, lethargy, anorexia [13]. The severe form of malaria often occurs in individuals not previously exposed to malaria such as young children and travelers from non-endemic areas, and often present clinically as cerebral malaria, pulmonary edema, acute kidney injury, hypoglycemia, lactic acidosis, anemia, and liver involvement [14]. Both Malaria and HBV infections can present with febrile illness associated with generalized body ache, weakness, headache and yellowish sclera as their first symptoms [15]. It has been estimated that about 2 billion people have been infected with HBV and more than 300 million people worldwide suffer from persistent infection [16]. Out of this, about 600,000 people die every year due to the acute or chronic consequences of the disease [17]. The prevalence rate of HBV infection is highest in the Sub-Saharan Africa and Eastern parts of Asia with 44\% of cirrhotic liver disease and $47 \%$ of hepatocellular carcinoma cases in Sub-Saharan Africa attributed to HBV [18]. The infection is largely acquired during childhood with $5-10 \%$ of the adults developing a chronic disease [15], and HBV accounts for over 360 million cases of chronic hepatitis and 620,000 deaths annually [8]. Despite being vaccine preventable, HBV infection remains a global health problem. Similarly, malaria remains a burden globally particularly in Sub-Saharan Africa and a major health threat worldwide [19]. It is one of the most widespread infectious diseases in the world [20]. According to a World health organization [8], there were 214 million new cases of malaria and 438,000 deaths worldwide, and over $41 \%$ of world's population remain exposed to this disease [8]. Over the last few years, the incidence of malaria has reduced considerably, raising the possibility that eradication might be possible in the future [11]. The estimated global incidence rate of malaria decreased by $21 \%$ between 2010 and 2015 and $41 \%$ between 2000 and 2015 [21]. Also, the proportion of the population at risk in sub-Saharan Africa infected with malaria parasites is estimated to have declined from $22 \%$ in 2005 to $17 \%$ in 2010 , and to $13 \%$ in $2015[21 ; 22$ ]. Due to the coincidence in the endemicity of HBV and Plasmodium infections, co-infection of HBV with Plasmodium may occur [23]. These two infections live some of their developmental stages within the liver, and hepatocyte damage in HBV infection may cause poor liver handling of malaria parasites [24] thus culminating in increased morbidity. In line with this, co-infection with Plasmodium parasite and HBV virus in individual may possibly influence progression of both agents and associated severity. It is on this background that this work determines the sero-prevalence of Hepatitis $B$ Virus profile and Plasmodium co-infection among patients attending hospitals in Wukari environs. Due to low vaccination rates and the fact that about $75 \%$ of the Nigerian population will be exposed to HBV [18], the risk of contracting HBV is quite significant. In a previous study conducted in a University located in Wukari, a Hepatitis B Surface Antigen (HBsAg) seroprevalence rate of $6.0 \%$ was observed [25]; which raises some level of concern. On the other hand, Nigeria is known for having the world's greatest malaria burden, recording approximately 51 million cases and 207,000 deaths annually, while $97 \%$ of the total population is at risk of infection [26]. Worthy of mention is the fact that malaria accounts for $60 \%$ of outpatient visits to hospitals [26]. Malaria and HBV infection are co-endemic throughout much of the tropical and Sub-Saharan Africa and they both present major threat to public health [27]. These facts are quite worrisome and even more alarming when HBV infection occurs concurrently with malaria. In 2010, the World Health Assembly resolved to recognize viral hepatitis as a global health problem [[28]. There remains a scarcity of research on people's knowledge, attitudes, and practices towards malaria in the majority of the federation, particularly in Northern Nigeria [29]. Also, not much study has been carried out on HBV in most parts of the country and much is not known about its epidemiology [25]. This study therefore became necessary, in that, it will describe the epidemiology of HBV and highlight the burden of the HBV and malaria co-infection in Wukari environs, identify gaps and make recommendations for improvements on surveillance and control of both infections. This study is therefore necessary to determine the sero-prevalence of Hepatitis B Virus and Plasmodium co-infection profile among patients in Wukari and environs. 


\section{Material and methods}

\subsection{Study area and population}

This study was carried out in the Department of Microbiology, Federal University Wukari, Taraba State, Nigeria. Wukari metropolis is a large town which is the Headquarter of Wukari Local Government Area of Taraba State. Geographically, Wukari lies between latitude $7^{\circ} 55^{\prime} 42^{\prime \prime}$ North and longitude $9^{\circ} 47^{\prime} 59^{\prime \prime}$ East. It has an area of 4,308 km2. Wukari is home to Federal University Wukari, National Open University of Nigeria study center and Kwararafa University. It is an important town in Taraba state, characterized with agricultural activities among other activities. The average annual temperature in Wukari is $26.8^{\circ} \mathrm{C}$, with March being the hottest month with an average temperature of $29.8^{\circ} \mathrm{C}$ and August has the lowest average temperature with $25.4^{\circ} \mathrm{C}$. The average precipitation is $1205 \mathrm{~mm}$. The major languages spoken are Jukun, Kutep, Tiv, Hausa and Fulani [25].

\subsection{Ethical approval}

A letter of introduction was obtained from the Department of Microbiology, Federal University Wukari, and ethical approval was obtained from the hospital management. The purpose and procedure of the study was explained to the volunteers, parents or caregivers and their consent was obtained for samples collection.

\subsection{Study design}

The study design is a community, hospital-based cross-sectional and experimental study. The essence of the research was explained to the target population and their consents were obtained after which blood samples were collected.

\subsection{Sample collection}

All materials (sterile tubes, syringes and needles, tourniquet, cotton swab) required for the collection of venous blood were assembled and labeling of the sterile plain containers with the subjects' identification numbers were done. About $5 \mathrm{ml}$ of blood samples were collected from seventy (70) participants aseptically by venipuncture and dispensed into sterile labeled tubes with anticoagulants. Thick smears of the blood samples were made at the spot on clean and greasefree slides. The blood samples were transported in an ice box to the laboratory. The whole blood was stored at $4-8^{\circ} \mathrm{C}$ in the refrigerator for up to 24 hours, but was not allowed to freeze.

\subsection{Analysis of samples for Plasmodium spp}

Analysis was performed using microscopic examination of thick smears and parasitemia (parasites $/ \mathrm{mL}$ of blood) was calculated in positive cases. Malaria Rapid Diagnostic Test (RDT) was performed using whole plasma samples from all individuals to confirm diagnoses, using a test kit from Standard Diagnostics, Inc.

\subsubsection{Procedure for Thick film}

The procedure for staining and viewing thick film to establish malaria parasitaemia was done according to the method described by [30].

\subsubsection{Rapid Diagnostic Test Procedure}

The procedure was carried out based on the manufacturer's instruction. All the kit components and specimens were brought to room temperature prior to testing. The test device was removed from the foil pouch and placed on a flat, dry surface. It was labelled with subject's ID number. About $5 \mu \mathrm{L}$ of the blood sample was dispensed into the round specimen well. Four drops of assay diluent were placed into the assay diluent well. After a range of 15 to 30 minutes, the results were read.

\subsubsection{Interpretation of Result}

Negative: One line " $\mathrm{C}$ " in the result window indicates that no Malaria P. falciparum antigen is present. Positive: Two lines "C" and "P.f" in the result window indicates P. falciparum positive. Invalid: No "C" line in the result window

\subsection{Analysis Of Samples for Hepatitis B Virus}

Serum samples were analyzed for the presence of HBV Surface Antigen (HBsAg), Surface Antibody (HBsAb), Core Antibody (HBcAb), Envelope Antigen (HBeAg) and Envelope Antibody (HBeAb) using HBV Combo Rapid Test Cassette by Acro Biotech, Inc. 


\subsection{Procedure for Hepatitis B profile test}

The test was carried out using the procedure outlined by the manufacturer of the kit used. All the kit components and specimens were brought to room temperature prior to testing. Clear plasma was separated from the blood which showed no sign of haemolysis. The test cassette was removed from the foil pouch and placed on a clean and level surface. It was labeled with subject's ID number. Holding the dropper vertically, 3 drops of the plasma sample were dispensed into each sample well of the test cassette respectively, without trapping air bubbles. The results were read within 15 to 20 minutes, but not later than 20 minutes.

\subsection{Interpretation of Results}

\subsubsection{For $H B s A g$, $H B s A b, H B e A g$}

Negative: One coloured line appears in the control line (C) and no apparent coloured line appears in the test region (T). Positive: Two distinct coloured lines appear, one at the control region $(\mathrm{C})$, the other at the test region (T). Invalid: Control line fails to appear.

For HBeAb, HBcAb,

Negative: Two distinct coloured lines appear, one at the control region (C), the other at the test region (T). Positive: One coloured line appears in the control region (C) and no apparent coloured line appears in the test region (T). Invalid: Control line fails to appear.

\subsection{Data/Statistical Analysis}

The sero-prevalence of HBV and HCV infection was calculated by using participants with positive sample as numerator and the total number of participant as denominator. The data obtained from this study were presented using descriptive statistics.

\section{Results}

The distribution of the subjects based on gender and age is presented in Table 1 below. Seventy subjects participated in this study. The age range of the participants tested across Hospitals in Wukari and environs was between 0 to 80 years; $34(48.6 \%)$ were males and $36(51.4 \%)$ were females.

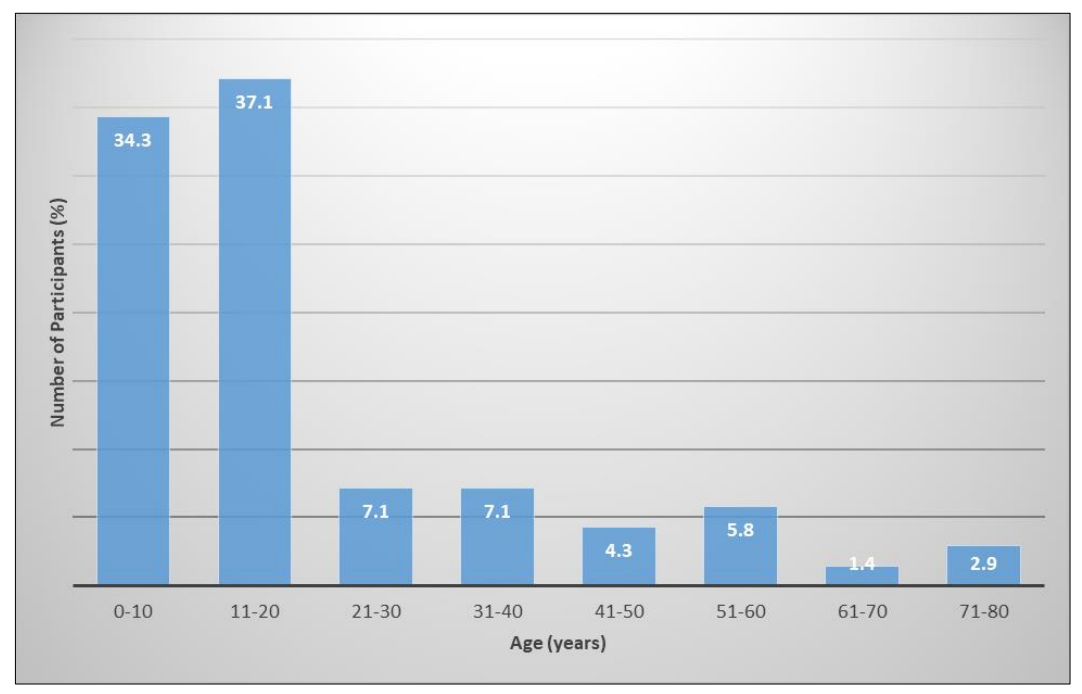

Figure 1 Bar Chart showing the percentage distribution of participants across various age group

Figure 1: Bar Chart showing the percentage distribution of participants across various age groups. Table 2 shows that $4(5.7 \%)$ persons out of 70 study participants were sero-positive for HBsAg. Other biomarkers were not detected. Equal sero-positivity rate was observed among the males with 2 sero-positives and females with 2 sero-positives. $5.9 \%$ of the Male participants were sero-positive while $5.6 \%$ of the female participants were sero-positive. Figure 2: Pie chart showing the overall Sero-prevalence of HBV among the study participants. Figure 3: Pie charts showing the Sero- 
prevalence of HBV among the male (A) and female (B) participants. Table 3 shows that $20(28.6 \%)$ of the participants were sero-positive for malaria. This comprises of 7 males and 13 females. $20.6 \%$ of the males were sero-positive while $36.1 \%$ of the females were sero-positive. Table 4 shows the distribution of parasitaemia by gender across the participants. 24 (34.3\%) had plasmodium parasitaemia, out of which 9 were males and 15 were females. $26.5 \%$ of the males and $41.7 \%$ of the females had plasmodium parasitaemia. In table 5, it was shown that there was no co-infection of Hepatitis B virus and malaria, despite both having prevalence of $5.7 \%$ and $34.3 \%$ respectively.

Table 1 Distribution of study participants based on gender and age group

\begin{tabular}{|c|c|c|c|}
\hline Age (Years) & Male & Female & Total (\%) \\
\hline $0-10$ & 10 & 14 & $24(34.3)$ \\
\hline $11-20$ & 15 & 11 & $26(37.1)$ \\
\hline $21-30$ & 4 & 1 & $5(7.1)$ \\
\hline $31-40$ & 2 & 3 & $5(7.1)$ \\
\hline $41-50$ & 2 & 1 & $3(4.3)$ \\
\hline $51-60$ & 1 & 3 & $4(5.8)$ \\
\hline $61-70$ & 0 & 1 & $1(1.4)$ \\
\hline $71-80$ & 0 & 2 & $2(2.9)$ \\
\hline Total & $34(48.6 \%)$ & $36(51.4 \%)$ & $70(100)$ \\
\hline
\end{tabular}

Table 2 Sero-prevalence of HBV by gender among the study participants

\begin{tabular}{|l|c|c|c|}
\hline \multicolumn{1}{|c|}{ Biomaker } & $\begin{array}{c}\text { Male (\%) } \\
\mathbf{n = 3 4}\end{array}$ & $\begin{array}{c}\text { Female (\%) } \\
\mathbf{n = 3 6}\end{array}$ & $\begin{array}{c}\text { Frequency (\%) } \\
\mathbf{n = 7 0}\end{array}$ \\
\hline $\mathrm{HBsAg}$ & $2(5.9)$ & $2(5.6)$ & $4(5.7)$ \\
\hline $\mathrm{HBsAb}$ & 0 & 0 & 0 \\
\hline $\mathrm{HBcAb}$ & 0 & 0 & 0 \\
\hline $\mathrm{HBeAg}$ & 0 & 0 & 0 \\
\hline HBeAb & 0 & 0 & 0 \\
\hline Total & $2(5.9)$ & $2(5.6)$ & $4(5.7)$ \\
\hline
\end{tabular}

Table 3 Sero-prevalence of Plasmodium falciparum antigen by gender among the study participants

\begin{tabular}{|l|c|c|}
\hline \multicolumn{1}{|c|}{ Sex } & No. of positive (\%) & No. of Negative (\%) \\
\hline Male $(n=34)$ & $7(20.6)$ & $27(79.4)$ \\
\hline Female $(n=36)$ & $13(36.1)$ & $23(63.9)$ \\
\hline Total $(n=70)$ & $20(28.6)$ & $50(71.4)$ \\
\hline
\end{tabular}


International Journal of Science and Research Archive, 2021, 03(01), 114-123

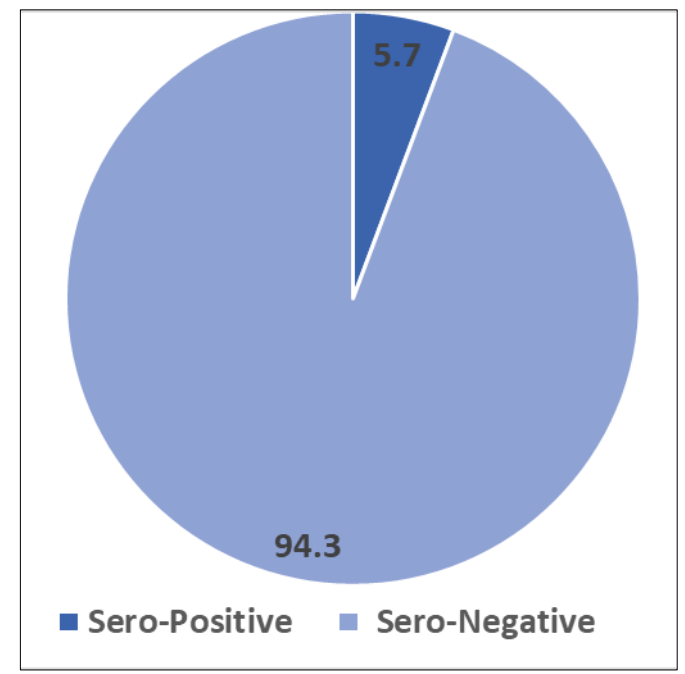

Figure 2 Pie chart showing the overall Sero-prevalence of HBV among the study participants

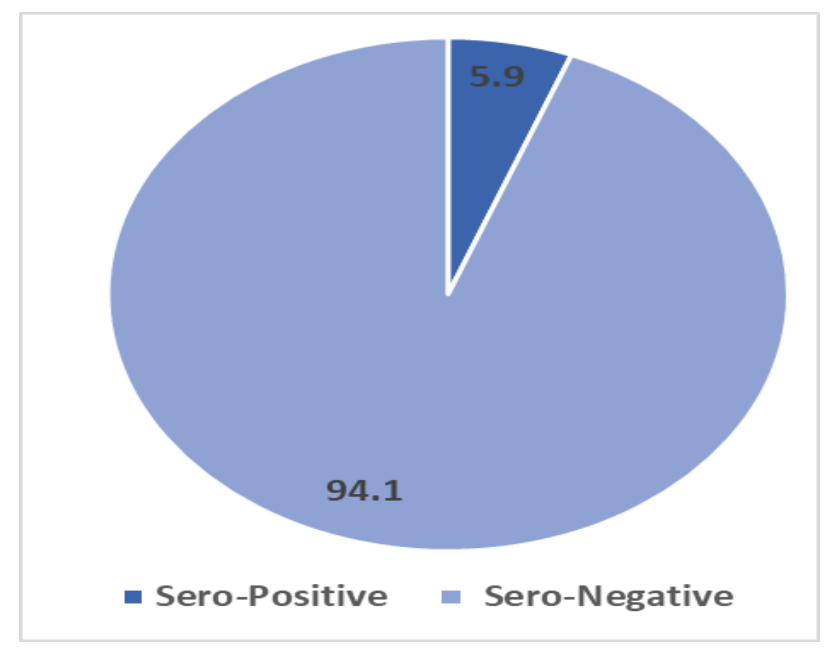

A

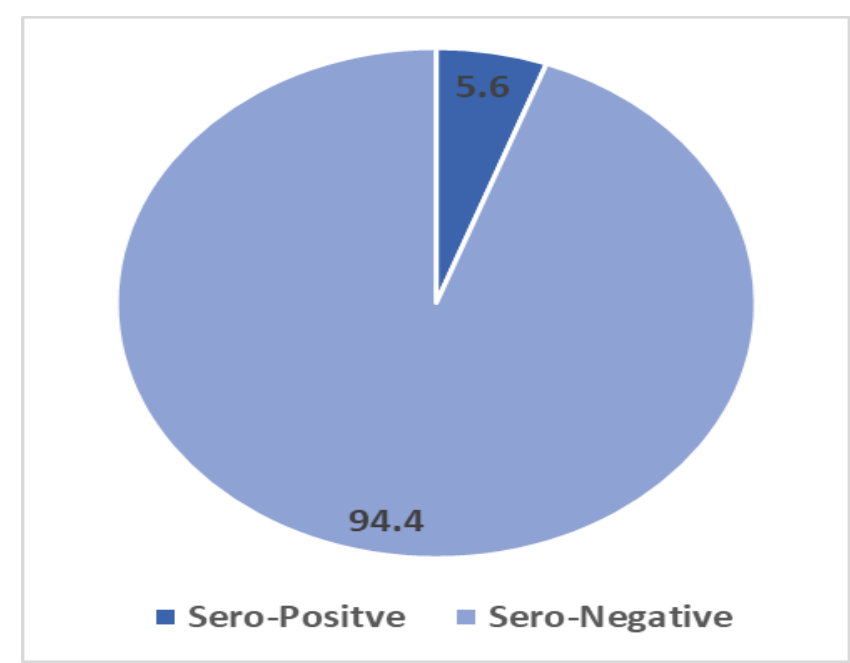

B

Figure 3 Pie charts showing the Sero-prevalence of HBV among the male (A) and female (B) participants

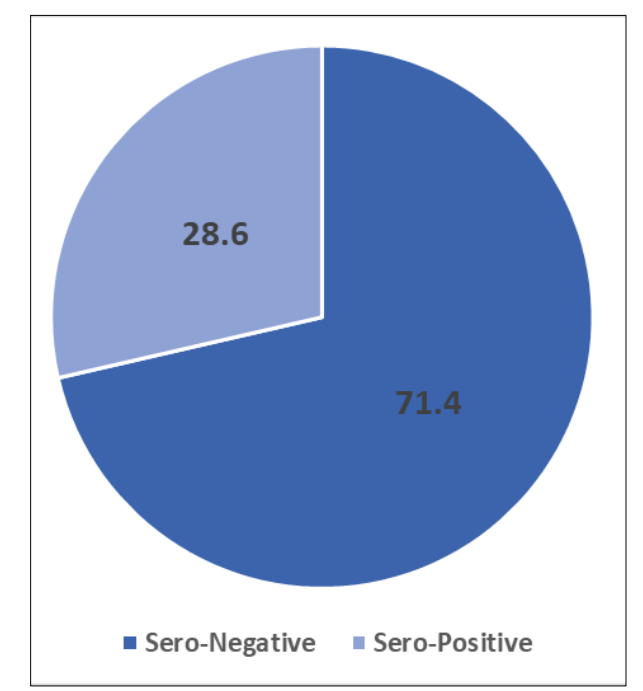

Figure 4 Sero-prevalence of Plasmodium falciparum antigen among the study participants 


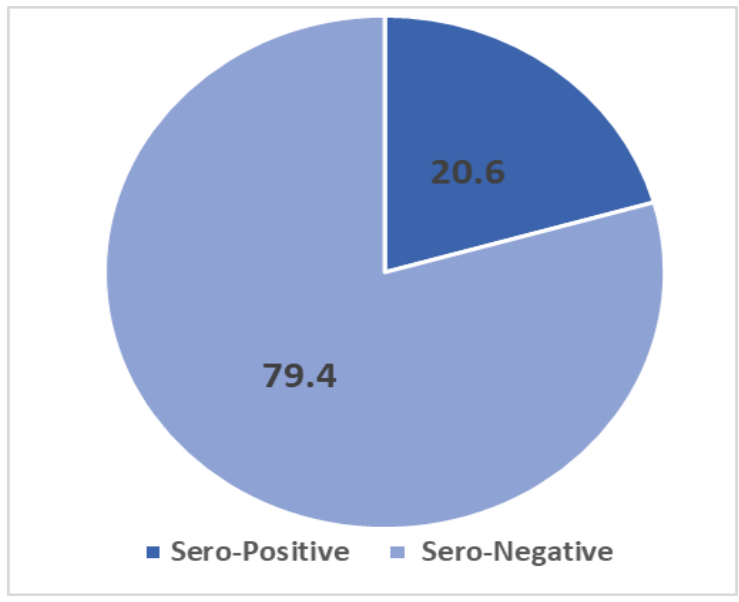

A

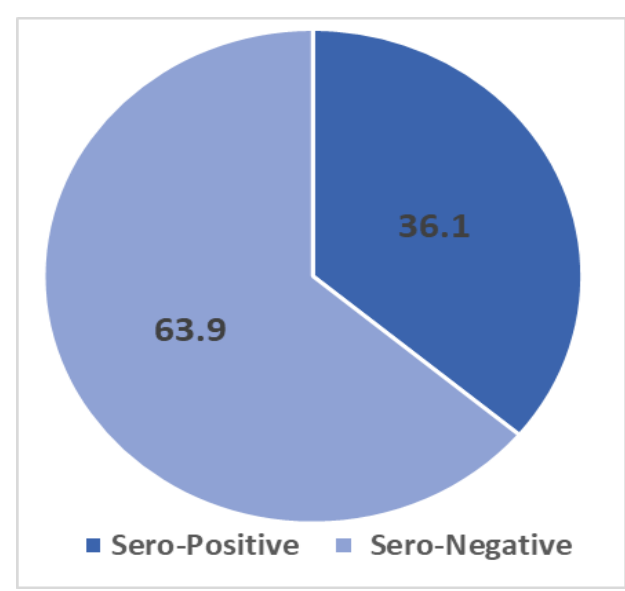

B

Figure 5 Pie charts showing sero-prevalence of Plasmodium falciparum antigen among the male (A) and female (B) participants.

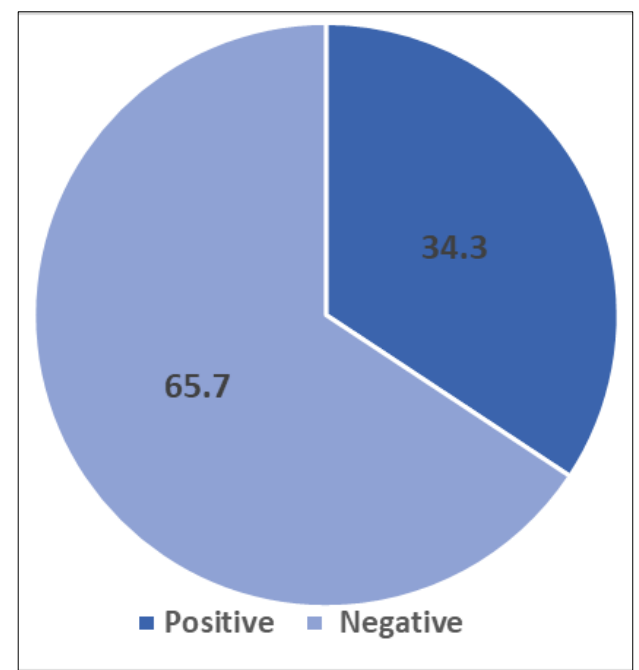

Figure 6 Prevalence of Plasmodium parasitaemia among the participants

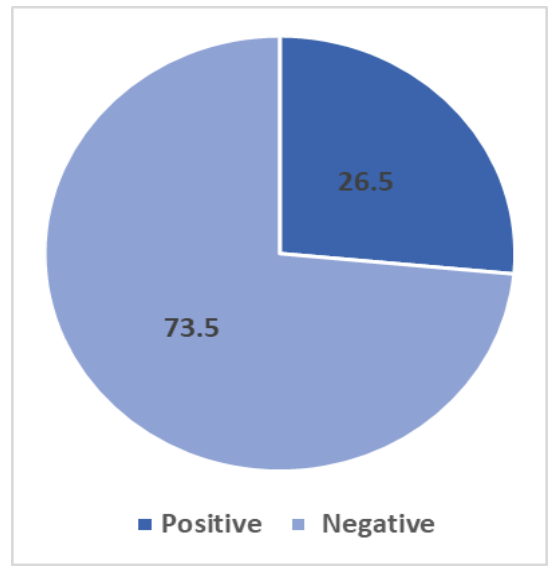

A

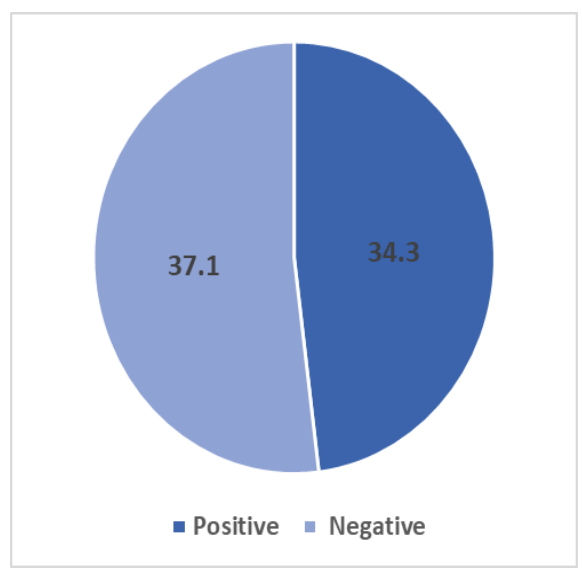

B

Figure 7 Pie chart showing the prevalence of Plasmodium parasitaemia among the male (A) and female (B) participants 
Table 4 Distribution of parasitaemia by gender across the participants

\begin{tabular}{|l|c|c|}
\hline Sex & No. of positive (\%) & No. of Negative (\%) \\
\hline Male $(n=34)$ & $9(26.5)$ & $25(73.5)$ \\
\hline Female $(n=36)$ & $15(41.7)$ & $21(58.3)$ \\
\hline Total $(n=70)$ & $24(34.3)$ & $46(65.7)$ \\
\hline
\end{tabular}

Table 5 Sero-prevalence of coinfections among participants $(n=70)$

\begin{tabular}{|l|c|c|}
\hline \multicolumn{1}{|c|}{ Infection } & No. of Positive (\%) & No. of Negative (\%) \\
\hline Malaria & $24(34.3)$ & $46(65.7)$ \\
\hline Hepatitis B & $4(5.7)$ & $66(94.3)$ \\
\hline Coinfection & $0(0.0)$ & $70(100.0)$ \\
\hline
\end{tabular}

\section{Discussion}

Hepatitis B Virus and plasmodium co- infections are both reportedly common in several tropical areas, and the endemicity of these infections often overlaps. The presence of malaria and HBV co-infection has been known to influence the progression of either malaria, hepatitis, or both diseases [31]. From the result generated in this study, there was an overall sero-prevalence rate of 5.7\% for HBsAg and prevalence rate of 34.3\% was recorded for malaria parasitaemia. No case of co-infection was observed. The prevalence rate (5.7\%) obtained in this study is close to $6.0 \%$ reported by [25] from Wukari and 6.5\% reported by [15] from Kano. The figure from this study is however; lower than 11\% reported by [32] from Kogi state, 11.5\% reported by [33] from Ekiti State and 12.3\% reported by [34]. [9] noted that there has been a downward trend in the prevalence of chronic HBV infection mainly due to immunization against HBV and improved health-care practices, for example, screening of blood and blood products, injection safety, and infection control policies and practices. The $34.3 \%$ prevalence rate of malaria infection presented by this study is close to $30.59 \%$ reported by [35] and 25.5\% reported by [15] both from Kano. It differed by a wide margin from $77.6 \%$ presented by [36] from Enugu. In this present study, females (34.3\%) had greater malaria burden than men (26.5\%). A similar observation was made by [15] who reported a prevalence rate of $18.0 \%$ in female than males with $7.5 \%$. This is also consistent with the findings by [35], who reported a prevalence rate of $61.0 \%$ in female than their male counterparts with $38.0 \%$. The $0 \%$ prevalence rate recorded in this study varied from most other studies where various rates of prevalence were reported. [37] recorded 5.5\% prevalence rate of HBV and malaria co-infection. [38] recorded a coinfection prevalence rate of 7.8\% among a group of pregnant Nigerian women. [15] recorded $4.5 \%$ in febrile patients in Kano. The difference could likely be related to the number of participants (70) recruited for this present study which is low compared to other related studies. On the other hand, it could be a proof that, there is decrease in the trend of malaria and HBV infections and that the effort at prevention and control of these two infections is reaching the target as noted by [15]. Numerous studies have been carried out on the prevalence of malaria infection, HBV infection and the coincidence of both infections.

\section{Conclusion}

Although much is known about the epidemiology of HBV and plasmodium infections in Nigeria, limited investigations have been carried out on HBV and plasmodium co-infections in some parts of the country. Studies carried out by various authors have shown that HBV and plasmodium co-infections are highly prevalent among Nigerians. The result of this study which shows that the prevalence of HBC (5.7\%) and plasmodium infections (34.3\%) which is high when compared with the study population shows that many of these patients do not know much about hepatitis viral infection, mode of transmission, vaccination, treatment, prevention and control hence the high prevalence rate recorded in this study population. As a result of this, there is need for adequate screening programme to reduce the transmission of infection. Public awareness programme to educate the populaces on modes of transmission should be put in place for HBV vaccination because many of the patients are not aware of the infection and its mode of transmission, some are afraid of taking vaccine for various reasons such as religion which in this part most people still believe that the use of drugs is against their religion. Therefore, in order to reduce HBV and plasmodium co-infection, mass immunization of adults and antiviral drugs should be provided for those that are infected, while HBV and plasmodium co-infections screening programs should be instituted in all levels of institutions in the country to reduce the prevalence rate and level of 
transmission of the hepatitis virus. This study has therefore, added to the pool of knowledge already available in this area of research. The result of this study showed that the prevalence rate of $\mathrm{HBV}$ and malaria infections are $5.7 \%$ and $34.3 \%$ respectively with no co-infection. This could be a pointer to the increasing awareness of people towards prevention of HBV and malaria infections. The data from this study can be relied upon and as well, further consolidated by subsequent studies.

\section{Compliance with ethical standards}

\section{Acknowledgments}

Heartfelt thanks go to the laboratory staff of the Department of Microbiology of Federal University Wukari, staff of general hospital Wukari as well staff of kwarafara hospital Wukari for their assistance and contributions.

\section{Disclosure of conflict of interest}

No conflict of interest reported. Authors unanimously agree with the publication of this scientific work.

\section{References}

[1] Guarino B. New strains of Hepatitis B Virus discovered in ancient human remains. The Washington Post. 2018.

[2] Van Hemert FJ, van de Klundert MA, Lukashov VV, Kootstra NA, Berkhout B, Zaaijer HL. Protein X of hepatitis B virus: origin and structure similarity with the central domain of DNA glycoslase. PLoS ONE. 2011; 6(8): e23392.

[3] Zhou Y, Holmes EC. Bayesian estimates of the evolutionary rate and age of Hepatitis B Virus. Journal of Molecular Evolution. 2007; 65(2): 197-205.

[4] Paraskevis D, Magiorkinis G, Magiorkinis E, Ho SY, Belshaw R, Allain JP, Hatzakis A. Dating the origin and dispersal of Hepatitis B Virus infection in humans and primates. Hepatology. 2013; 57(3): 908-916.

[5] Littlejohn M, Locarnini S, Yuen L. Origins and Evolution of Hepatitis B Virus and Hepatitis D Virus. Cold Spring Harbor Perspectives in Medicine. 2016; 6(1): a021360.

[6] Rasche A, Souza BF, Drexler JF. Bat hepadnaviruses and the origins of primate Hepatitis B Viruses. Current Opinion in Virology. 2016; 16: 86-94.

[7] Bouckaert R, Simons BC, Krarup H, Friesen TM, Osiowy C. Tracing Hepatitis B Virus (HBV) genotype B5 (formerly B6) evolutionary history in the circumpolar Arctic through phylogeographic modelling. Peer Journal. 2017; 5: e3757.

[8] World Health Organization. Guidelines for the Prevention, Care and Treatment of Persons with Chronic Hepatitis B Infection. 2015.

[9] Olayinka AT, Oyemakinde A, Balogun MS, Ajudua A, Nguku P, Aderinola M, Egwuenu-Oladejo A, Ajisegiri SW, Sha'aibu S, Musa BOP, Gidado S, Nasidi A. American Journal of Tropical Medicine and Hygiene. 2016; 95(4): $902-$ 907.

[10] Ukaegbu CO, Nnachi AU, Mawak JD, Igwe CC. Incidence of Concurrent Malaria and Typhoid Fever Infections in Febrile Patients in Jos, Plateau State Nigeria. International Journal of Scientific and Technology Research. 2014; 3(4): 157-161.

[11] Tuteja R. Introduction to the Special Issue on Malaria. The Federation of European Biochemical Societies Journal. 2017; 284: 2550-2552.

[12] Tusting LS, Ippolito MM, Willey BA, Kleinschimdt I, Dorsey G. The evidence for improving housing to reduce malaria: a systematic review and metaanalysis. Malaria Journal. 2015; 14(1): 209.

[13] Khanam S. Prevalence and Epidemiology of Malaria in Nigeria: A Review. International Journal of Research in Pharmacy and Biosciences. 2017; 4(8): 10-12.

[14] Tizifa TA, Kabaghe AN, McCann RS, van den Berg H, Van Vugt M, Phiri KS. Prevention Efforts for Malaria. Current Tropical Medicine Reports. 2018; 5: 41-50.

[15] Sharif AA, Dabo NT, Getso MI. Prevalence of malaria and Hepatitis B Virus infection in febrile patients in Kano northwest Nigeria. International Journal of Current Research and Review. 2015; 7(9): 61-65. 
[16] World Health Organization [WHO]. World Malaria report 2015. Genève: WHO. 2015; 280.

[17] Wong F, Pai R, Van Schalkwyk J, Yoshida EM. Hepatitis B in pregnancy: a concise review of neonatal vertical transmission and antiviral prophylaxis. Annals of Hepatology. 2014; 13(2): 187-195.

[18] Musa B, Bussell S, Borodo MM, Samaila AA, Femi OL. Prevalence of Hepatitis B Virus infection in Nigeria, 2000-2013: A systematic review and meta-analysis. Nigerian Journal of Clinical Practice. 2015; 18: 163-172.

[19] Yan H, Liu Y, Sui J, Li W. NTCP opens the door for Hepatitis B Virus infection. Antiviral Research. 2015; 121: 2430 .

[20] Scotto G, Fazio V. Hepatitis B and asymptomatic malaria coinfection in Sub-Saharan African immigrants: epidemiological and clinical features of HBV infection. Revista da Sociedade Brasileira de Medicina Tropical. 2018; 51(5): 578-583.

[21] World Health Organization [WHO]. World malaria report 2017. Geneva. 2017.

[22] World Health Organization [WHO]. World malaria report 2018. Geneva. 2016.

[23] Friemanis GL, Owuso-Ofori S, Allain JP. Hepatitis B Virus Infection does not significantly influence Plasmodium parasite density in asymptomatic infections in Ghanian transfusion recipients. PLoS ONE. 2012; 7(11): e49967.

[24] Paulyn TA, Terdzungwe TS. Prevalence of plasmodia and HBV co-infection in blood donors at Bishop Murray Murray Medical Centre, Markurdi, Benue State, Nigeria: Asian Pacific Journal of Tropical Medicine. 2010; 22-26.

[25] Imarenezor EPK, Brown STC, Yakubu OE, Soken DC. Survey of Hepatitis B and C among students of Federal University Wukari, Taraba State, Nigeria. International Research Journal of Medicine and Medical Sciences. 2016; 4(3): 31-37.

[26] World Health Organization [WHO]. Antimicrobial resistance: global report on surveillance. 2014.

[27] Jeya DB, Botelho de suza RA, Batista da Silva E. Co-human infection by Plasmodium and hepatitis B: Clinical aspect, Immunological and Serological: Tropical Medicine Foundation of Amazon. 2010.

[28] World Health Organization [WHO]. Global policy report on the prevention and control of viral hepatitis. 2010.

[29] Zhang Z, Zehnder B, Damrau C, Urban S. Visualization of Hepatitis B Virus entry - novel tools and approaches to directly follow virus entry into hepatocytes. FEBS Letters. 2016; 590(13): 1915-1926.

[30] Cheesbrough M. District Laboratory Practice in Tropical Countries Part 1 (2nd Ed.). Cambridge University Press, Cambridge, UK. 2009; 239-258.

[31] Aernan PT, Sar TT, Torkula SH. Prevalence of Plasmodia and hepatitis B virus co-infection in blood donors at Bishop Murray Medical Centre, Makurdi, Benue State, Nigeria. Asian Pacific Journal of Tropical Medicine. 2011; 4(3): 224-226.

[32] Sule WF, Okonko IO, Ebute AJ, Donbraye E, Fadeyi A, Udeze AO, Alli JA. Farming and non-farming individuals attending grimard catholic Hospital Anyingba Kogi State Nigeria, were Comparable in Hepatitis B surface antigen Seroprevalence. Current Research Journal of Biological Sciences. 2010; 2(4): 278-282.

[33] World Health Organization [WHO]. Global policy report on the prevention and control of viral hepatitis. 2012.

[34] Hamza M, Samaila AA, Yakasai AM, Babashani M, Borodo MM, Habib AG. Prevalence of Hepatitis B and C virus infections among HIV-infected patients in a tertiary hospital in North western Nigeria. Nigerian Journal of Basic Clinical Science. 2013; 10: 76-81.

[35] Gobir Z, Tukur Z. Prevalence of Malaria parasitemia using rapid diagnostic test among apparently healthy children in Kano, Nigeria. Journal of Medical Trop. 2014; 1(6): 1-4.

[36] Igwe NM, Joannes UO, Chukwuma OB, Chukwudi OR, Oliaemeka EP, Maryrose AU, Joseph A. Prevalence and parasite density of asymptomatic malaria parasiteamia among unbooked paturients at Abakaliki, Nigeria. Journal of Basic Clinical and Reproductive Science. 2014; 3: 44-48.

[37] World Health Organization [WHO]. The expanded Programme on immunization. Geneva. 2018.

[38] Omalu ICJ, Jibrin A, Olayemi IK, Hassan SC, Mgbemena C, Mgbemena A, et al. Seroprevalence of malaria and hepatitis B (HBsAg) with associated risk factors among pregnant women attending antenatal clinic in general hospital Minna, North-Central Nigeria. Annual Review in Research Biology. 2012; 2(4): 83-88. 